\title{
Structure of a minor reaction product formed via base promoted hydrolysis of Thiele's ester
}

\author{
William H. Watson, ${ }^{* a}$ Alan P. Marchand, ${ }^{* b}$ and Rasapalli Sivappa ${ }^{b}$ \\ ${ }^{a}$ Department of Chemistry, Texas Christian University, Fort Worth, Texas 76129-8860 \\ ${ }^{b}$ Department of Chemistry, University of North Texas, Denton, Texas 76203-5070 \\ E-mail:w.watson@tcu.edu; marchand@unt.edu
}

Praca dedykowana Profesorowi Mieczyslawowi Makoszy z okazji jego 70-tych urodzin

(received 23 Sep 03; accepted 10 Dec 03; published on the web 15 Dec 03)

\begin{abstract}
Base promoted hydrolysis of dimethyl 3a $\alpha, 4 \alpha, 7 \alpha, 7 a \alpha$-tetrahydro-4,7-methano-l $H$-indene-2,5dicarboxylate (i.e., "Thiele's ester", 2), performed by using $\mathrm{KOH}-\mathrm{MeOH}$, afforded after aqueous acidic workup the corresponding diacid (i.e., "Thiele's acid", 1) along with a minor reaction product, $\mathbf{3}$. Compound $\mathbf{3}$ has been shown to possess structure $\mathbf{3 a}$ via application of single crystal $\mathrm{X}$-ray crystallographic techniques.
\end{abstract}

Keywords: Michael addition, selective ester hydrolysis, X-ray crystal structure determination

\section{Introduction}

Carbonation of sodium cyclopentadienide leads to the formation of $3 a \alpha, 4 \alpha, 7 \alpha, 7 a \alpha$-tetrahydro4,7-methano-l $H$-indene-2,6-dicarboxylic acid ${ }^{1}$ [i.e., "Thiele's acid", 1, 60\%] along with several isomeric $\mathrm{C}_{12} \mathrm{H}_{12} \mathrm{O}_{4}$ minor products. ${ }^{2}$ Recently, our attention has turned to Thiele's acid as a potentially useful intermediate in the synthesis of unusual polycarbocyclic systems. ${ }^{2,3}$

In connection with ongoing research projects, it was necessary for us to prepare isomerically pure Thiele's acid in quantity. To this end, the crude mixture of carboxylic acids obtained via carbonation of sodium cyclopentadienide was esterified by using $\mathrm{MeOH}-\mathrm{H}_{2} \mathrm{SO}_{4}$. Pure Thiele's ester, 2 (Scheme 1), mp $85^{\circ} \mathrm{C},{ }^{1}$ could be isolated in good yield via fractional recrystallization of the mixture of esterification products from 10\% EtOAc-hexane mixed solvent. 

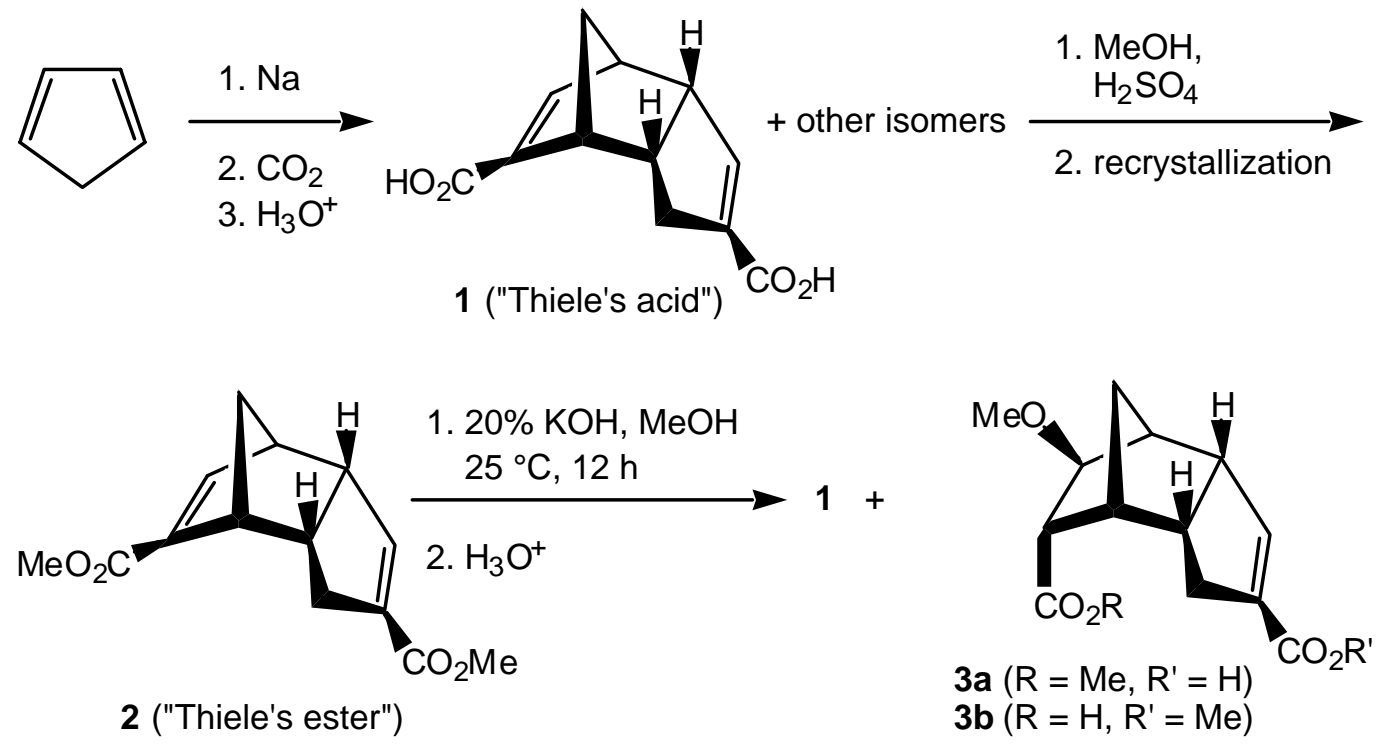

\section{Scheme 1}

Subsequently, purified Thiele's ester was subjected to base promoted hydrolysis by using $\mathrm{KOH}-\mathrm{MeOH}$ followed by aqueous acidic workup. As expected, Thiele's acid was obtained as the major reaction product. Pure Thiele's acid was obtained in an overall yield of $47 \%$ via application of the reaction sequence shown in Scheme 1. In addition, this material was accompanied by a second, minor product, $\mathbf{3}$, which was obtained in $10 \%$ yield. Inspection of the ${ }^{1} \mathrm{H}$ and ${ }^{13} \mathrm{C}$ NMR spectra of $\mathbf{3}$ suggested that base promoted hydrolysis of $\mathbf{2}$ might have been accompanied by Michael addition of $\mathrm{MeO}^{-}$to one of the two nonequivalent $\alpha, \beta$-unsaturated ester moieties in $\mathbf{2}$.

Apropos of the present study, we recently elucidated the structure of a minor reaction product, 3c (Scheme 2), formed during acid promoted esterification of Thiele's acid. ${ }^{4}$ The similarity between ${ }^{1} \mathrm{H}$ and ${ }^{13} \mathrm{C}$ NMR spectra of $\mathbf{3}$ and $\mathbf{3 c}$ suggested that these two compounds are structurally very similar. However, on the basis of NMR spectral analysis alone, a clear choice could not be made between structures $\mathbf{3 a}$ and $\mathbf{3 b}$ for the minor product, $\mathbf{3}$, formed via reaction of 2 with $\mathrm{KOH}-\mathrm{MeOH}$. Accordingly, we turned to single crystal X-ray crystallographic analysis to provide unequivocal resolution to this question.
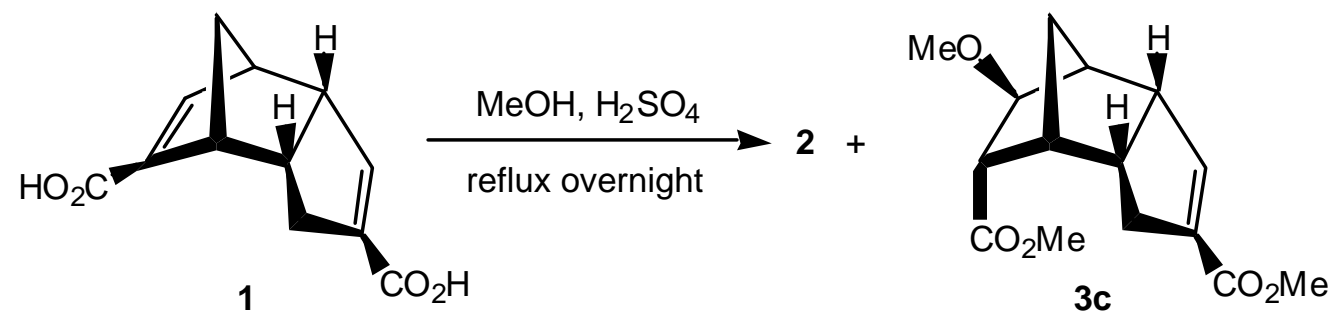

\section{Scheme 2}




\section{Results and Discussion}

X-Ray crystal structure of the minor reaction product formed via base promoted hydrolysis of 2. A thermal ellipsoid plot of the minor reaction product, $\mathbf{3}$, is shown in Figure 1; the corresponding packing diagram, which shows intermolecular interactions, is presented in Figure 2. Therein, it can be seen that the minor reaction product possesses structure 3a rather than $\mathbf{3 b}$. Crystal and refinement data for $\mathbf{3 a}$ are presented in Table 1.

As with most carboxylic acids, the molecules form strongly hydrogen bonded dimers, [see Figure 3; therein, $\mathrm{O}(5)-\mathrm{H}(14) \cdots \mathrm{O}(4 \mathrm{~A}), \mathrm{O}(5)-\mathrm{H}(4)=1.02(4) \AA, \mathrm{H}(14) \cdots \mathrm{O}(4 \mathrm{~A})=1.62(4) \AA$, $\mathrm{O}(5)^{\cdots} \mathrm{O}(4 \mathrm{~A})=2.631(4) \AA$, and $\left.\mathrm{O}(5)-\mathrm{H}(14)^{\cdots} \mathrm{O}(4 \mathrm{~A})=172(4)^{\circ}\right]$. The carboxylic acid hydrogen atom was found in the difference map and was refined. The strength of the hydrogen bond is also reflected in the almost equivalent $\mathrm{C}-\mathrm{O}$ distances $[\mathrm{C}(14)-\mathrm{O}(4)=1.236(3) \AA$ and $\mathrm{C}(14)-\mathrm{O}(5)=$ 1.290(3) $\AA$ ]. The two carboxylic acid groups in the hydrogen bonded dimer are related by a center of symmetry. The cyclopentene ring is planar; in addition, the carboxylic acid group, $\mathrm{C}(14)$, and the ester group, C(11) are essentially coplanar (Figure 1).

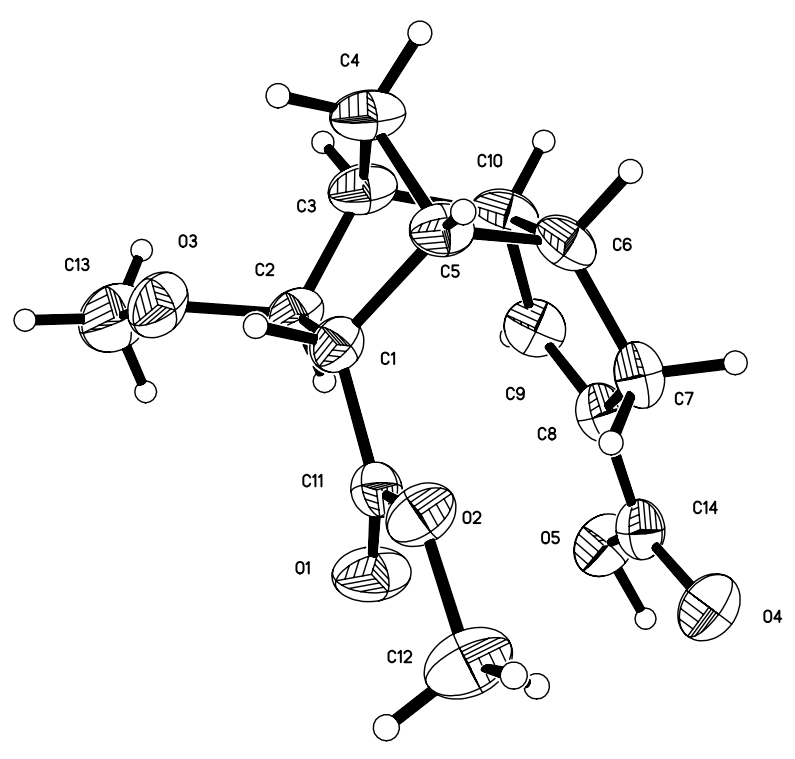

Figure 1. Thermal ellipsoid plot of 3a. 


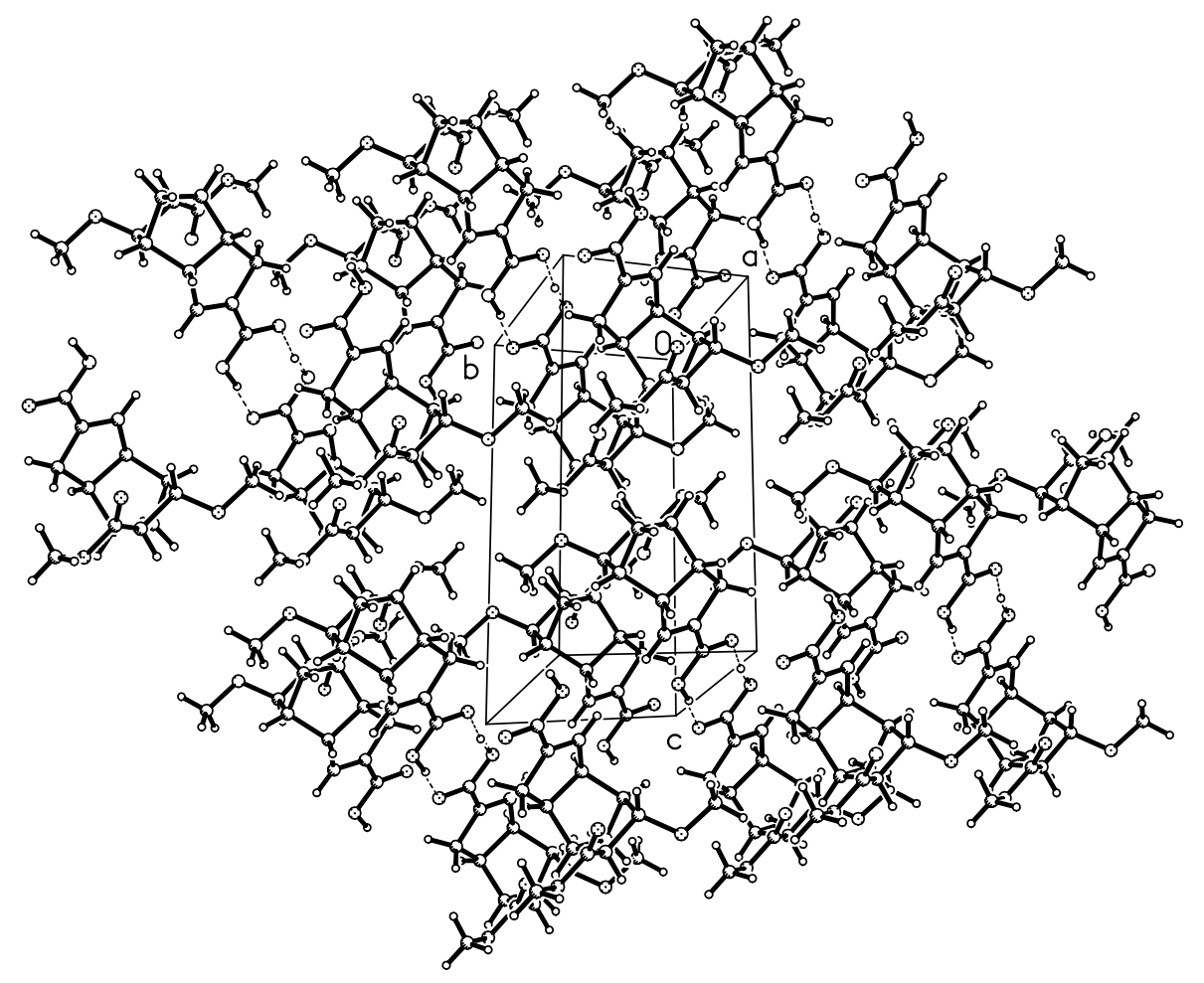

Figure 2. Crystal packing diagram for 3a.

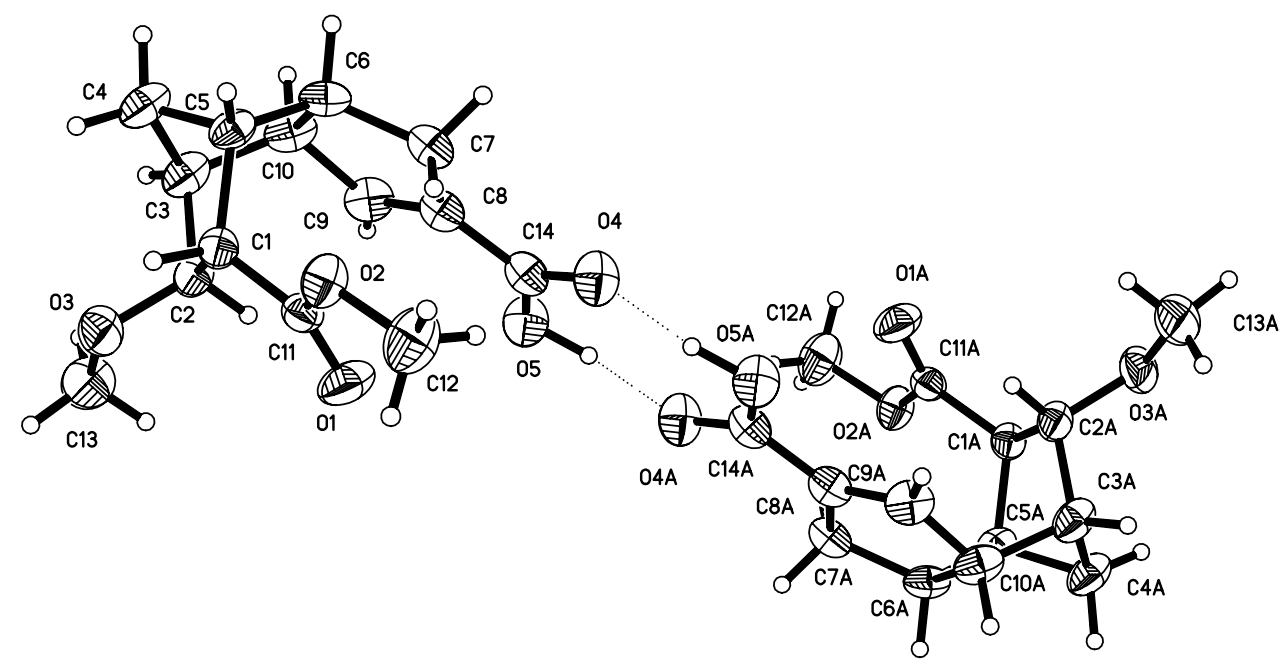

Figure 3. Thermal ellipsoid plot of the hydrogen bonded dimer of $\mathbf{3 a}$. 
Table 1. Crystal data and structure refinement for 3a

\begin{tabular}{|c|c|c|}
\hline Empirical formula & \multicolumn{2}{|l|}{$\mathrm{C}_{14} \mathrm{H}_{18} \mathrm{O}_{5}$} \\
\hline Formula weight & \multicolumn{2}{|l|}{266.28} \\
\hline Temperature & \multicolumn{2}{|l|}{$300(2) \mathrm{K}$} \\
\hline Wavelength & \multicolumn{2}{|l|}{$0.71073 \AA$} \\
\hline Crystal system & \multicolumn{2}{|l|}{ Triclinic } \\
\hline Space group & \multicolumn{2}{|l|}{ P-1 } \\
\hline \multirow[t]{3}{*}{ Unit cell dimensions } & $a=6.784(7) \AA$ & $\alpha=73.037(16)^{\circ}$. \\
\hline & $\mathrm{b}=8.319(8) \AA$ & $\beta=86.368(16)^{\circ}$. \\
\hline & $c=13.237(13) \AA$ & $\gamma=67.809(15)^{\circ}$. \\
\hline Volume & \multicolumn{2}{|l|}{$660,7(11) \AA^{3}$} \\
\hline $\mathrm{Z}$ & \multicolumn{2}{|l|}{2} \\
\hline Density (calculated) & \multicolumn{2}{|l|}{$1.338 \mathrm{Mg} / \mathrm{m}^{3}$} \\
\hline Absorption coefficient & \multicolumn{2}{|l|}{$0.101 \mathrm{~mm}^{-1}$} \\
\hline $\mathrm{F}(000)$ & \multicolumn{2}{|l|}{284} \\
\hline Crystal size & \multicolumn{2}{|c|}{$0.60 \times 0.36 \times 0.33 \mathrm{~mm}^{3}$} \\
\hline Theta range for data collection & \multicolumn{2}{|c|}{2.76 to $25.00^{\circ}$. } \\
\hline Index ranges & \multicolumn{2}{|c|}{$-8<=\mathrm{h}<=8,-9<=\mathrm{k}<=9,-15<=\mathrm{l}<=15$} \\
\hline Reflections collected & \multicolumn{2}{|c|}{4723} \\
\hline Independent reflections & \multicolumn{2}{|c|}{$2299[\mathrm{R}(\mathrm{int})=0.128]$} \\
\hline Completeness to theta $=25.00^{\circ}$ & \multicolumn{2}{|l|}{$99.3 \%$} \\
\hline Absorption correction & \multicolumn{2}{|l|}{ Empirical } \\
\hline Max. and min. transmission & \multicolumn{2}{|l|}{0.973 and 0.704} \\
\hline Refinement method & \multicolumn{2}{|c|}{ Full-matrix least-squares on $\mathrm{F}^{2}$} \\
\hline Data / restraints / parameters & \multicolumn{2}{|l|}{2299 / 0 / 179} \\
\hline Goodness-of-fit on $\mathrm{F}^{2}$ & \multicolumn{2}{|l|}{1.095} \\
\hline Final R indices [I $>2 \operatorname{sigma}(\mathrm{I})]$ & \multicolumn{2}{|c|}{$\mathrm{R} 1=0.0458, \mathrm{wR} 2=0.1326$} \\
\hline $\mathrm{R}$ indices (all data) & \multicolumn{2}{|c|}{$\mathrm{R} 1=0.0545, \mathrm{wR} 2=0.1409$} \\
\hline Extinction coefficient & \multicolumn{2}{|c|}{$0.018(6)$} \\
\hline Largest diff. peak and hole & \multicolumn{2}{|c|}{0.594 and $0.169 \mathrm{e} \cdot \AA^{-3}$} \\
\hline
\end{tabular}

Mechanistic rationalization. Thiele's ester contains two $\alpha, \beta$-unsaturated ester moieties, either or both of which might undergo Michael addition by methoxide ion. One of these moieties contains a norbornene $C=C$ double bond, whereas the $C=C$ double bond in the remaining $\alpha, \beta$ unsaturated ester moiety resides in a cyclopentene ring. In our hands, Michael addition of $\mathrm{MeO}^{-}$ occurred exclusively at the $\beta$-position in the norbornene $\mathrm{C}=\mathrm{C}$ double bond to afford 3a. It is likely that relief of additional steric strain present in the norbornene $\mathrm{C}=\mathrm{C}$ vis-à-vis that associated with the cyclopentene $\mathrm{C}=\mathrm{C}$ provides a driving force for nucleophilic attack at the former position. The fact that attack by $\mathrm{MeO}^{-}$occurs preferentially via the exo face of the norbornene 
$\mathrm{C}=\mathrm{C}$ bond is consistent with earlier observations ${ }^{5}$ with regard to the course of conjugate addition of nucleophiles to methyl 2-norborna-2,5-dienecarboxylate.

Furthermore, the additional strain present in the norbornene $\mathrm{C}=\mathrm{C}$ is expected to destabilize the ground state resonance form, 2a (Scheme 3), relative to the higher energy, charge-separated canonical form, $\mathbf{2 b}$ (Scheme 3), thereby minimizing norbornene $\mathrm{C}=\mathrm{C}$ double bond character in the resonance hybrid. This effect is expected to render the carbon atom $\beta$ - to the $\mathrm{C}=\mathrm{O}$ group in the norbornene $\alpha, \beta$-unsaturated ester moiety more highly electrophilic (due to increased $\delta^{+}$ charge at the $\beta$-carbon atom in the resonance hybrid) than would be the case in the less highly strained $\alpha, \beta$-unsaturated ester system situated within the cyclopentene ring in Thiele's ester. As a consequence, the norbornene $\mathrm{C}=\mathrm{C}$ is rendered more highly reactive toward nucleophilic attack by $\mathrm{MeO}^{-}$, a conclusion that is consistent with our experimental observations.
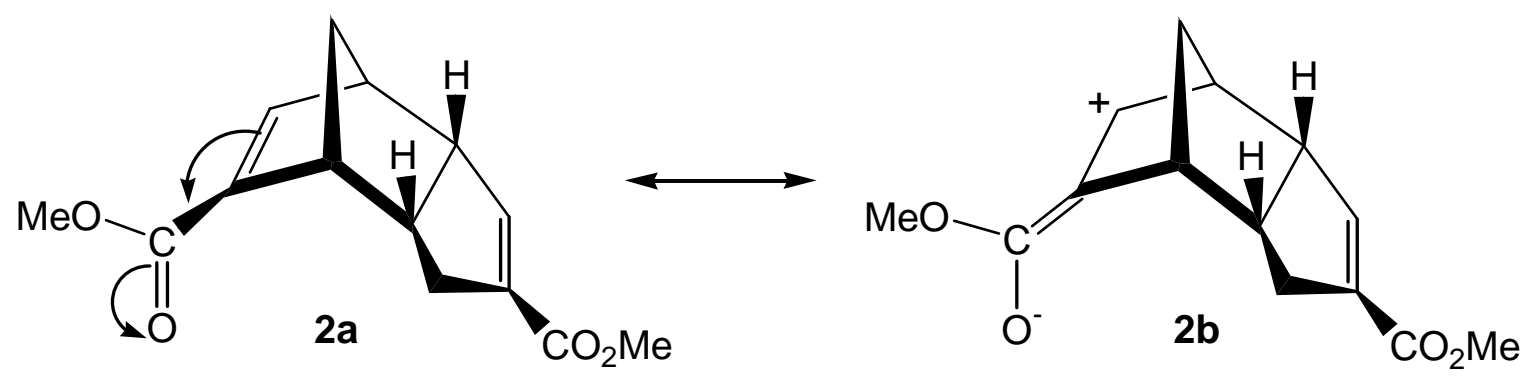

\section{Scheme 3}

Finally, the somewhat increased importance of the resonance contribution of the chargeseparated canonical form in the norbornene $\alpha, \beta$-unsaturated ester moiety, i.e., $\mathbf{2 b}$, is expected to reduce the $\mathrm{C}=\mathrm{O}$ double bond character in the associated ester group, thereby rendering this $\mathrm{CO}_{2} \mathrm{Me}$ group more resistant to base promoted hydrolysis than the corresponding ester group in the cyclopentene $\alpha, \beta$-unsaturated ester moiety. The conclusion that the cyclopentene $\mathrm{CO}_{2} \mathrm{Me}$ group in Thiele's ester thus is expected to be the more highly susceptible of the two ester functionalities toward base promoted ester hydrolysis is consistent with the experimentally observed preferential formation of $\mathbf{3 a}$.

\section{Experimental Section}

General Procedures. Melting points are uncorrected. High-resolution mass spectral data reported herein were obtained at the Mass Spectrometry facility at the Department of Chemistry and Biochemistry, University of Texas at Austin, by using a ZAB-E double sector highresolution mass spectrometer (Micromass, Manchester, England) that was operated in the chemical ionization mode. 
Base promoted hydrolysis of Thiele's ester. A mixture of 2 (9.60 g $38.7 \mathrm{mmol}$ ) and 20\% aqueous $\mathrm{KOH}(6.48 \mathrm{~g}, 116 \mathrm{mmol})$, in 50\% aqueous $\mathrm{MeOH}(60 \mathrm{~mL})$ was stirred at ambient temperature during $12 \mathrm{~h}$. The reaction mixture was concentrated in vacuo to remove excess methanol, and the resulting aqueous suspension was extracted with EtOAc ( $25 \mathrm{~mL})$. The aqueous layer was acidified by careful, dropwise addition with stirring of $10 \%$ aqueous $\mathrm{HCl}$, whereupon a white precipitate formed. The precipitate was isolated by suction filtration and then was air dried to afford 1 (7.43 g, 85\%) as a colorless microcrystalline solid: mp $211^{\circ} \mathrm{C}$ (lit. mp $212{ }^{\circ} \mathrm{C}$ ). ${ }^{1}$ The IR, ${ }^{1} \mathrm{H}$ NMR, and ${ }^{13} \mathrm{C}$ NMR spectrum of the material thereby obtained were essentially identical with the corresponding published spectral data for authentic $\mathbf{1}^{6}$

The filtrate was extracted with $\mathrm{CH}_{2} \mathrm{Cl}_{2}(2 \times 50 \mathrm{~mL})$. The combined organic extracts were dried $\left(\mathrm{Na}_{2} \mathrm{SO}_{4}\right)$ and filtered, and the filtrate was concentrated in vacuo. The residue was recrystallized from EtOAc, thereby affording pure 5-methoxycarbonyl-6-methoxy3a $\beta, 4 \alpha, 5 \beta, 6 \alpha, 7 \alpha, 7 \mathrm{a} \beta$-hexahydro-4,7-methanoindene-2-carboxylic acid (3a, $1.0 \mathrm{~g}, 10 \%)$ as a colorless microcrystalline solid: mp 169-170 ${ }^{\circ} \mathrm{C}$; IR (KBr) 3411 (br, m), 2972 (br, s) 2613 (m),

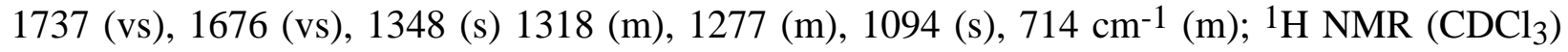
$\delta 1.45\left(\mathrm{AB}, J_{\mathrm{AB}}=11.2 \mathrm{~Hz}, 1 \mathrm{H}\right), 1.75\left(\mathrm{AB}, J_{\mathrm{AB}}=11.2 \mathrm{~Hz}, 1 \mathrm{H}\right), 2.14-2.58(\mathrm{~m}, 2 \mathrm{H}), 2.59-2.89$ (m, $4 \mathrm{H}), 3.22$ (s, $3 \mathrm{H}), 3.28$ (m, $1 \mathrm{H}), 3.63$ (s, $3 \mathrm{H}) 3.72$ (m., $1 \mathrm{H}) 6.73$ (d, $J=2.1 \mathrm{~Hz}, 1 \mathrm{H}) ;{ }^{13} \mathrm{C}$ NMR ( $\left.\mathrm{CDCl}_{3}\right) \delta 30.2$ (t), 39.8 (t), 41.2 (d), 43.4 (d), 44.7 (d), 51.4 (d), 51.5 (d), 53.6 (q), 55.8 (q), 80.0 (d) 136.0 (s), 144.7 (d), 169.4 (s), 172.7 (s). Exact MS: [ $\left.M_{\Gamma}+1\right]^{+}$calcd for $\mathrm{C}_{14} \mathrm{H}_{19} \mathrm{O}_{5}$, $\mathrm{m} / \mathrm{z}$ 267.1232. Found (high-resolution chemical ionization mass spectrometry): $\mathrm{m} / \mathrm{z}$ 267.1237.

X-Ray crystal structure of 3a. All X-ray data were collected on a Bruker SMART ${ }^{\mathrm{TM}} 1000$ CCD-based diffractometer. A total of 1,800 frames were collected at 10 sec per frame and integrated via the SAINT software package ${ }^{7}$ using a narrow frame algorithm. The structure was solved by using the SHELXTL program package. ${ }^{8}$ The data were analyzed and corrected for absorption by using the $S A D A B S^{7}$ program.

\section{Acknowledgments}

We thank the Robert A. Welch Foundation [Grants P-0074 (W. H. W.) and B-0963 (A. P. M.)], the U. S. Department of Energy [Grant DE-FG07-98ER14936 (A. P. M.)], and the National Science Foundation [Grant CHE-0315337 (A. P. M.)] for financial support of this study.

\section{Supplementary Information}

The X-ray data has been deposited with the Cambridge Crystallographic Data Centre and has been allocated deposition number 220111. A copy may be obtained by writing to CCDC, University Chemistry Laboratory, Lensfeld Road, Cambridge, CB2 1EW, United Kingdom. 


\section{References}

1. (a) Thiele, J. Chem. Ber. 1900, 33, 666. (b) Thiele, J. Chem. Ber. 1901, 34, 68.

2. Marchand, A. P.; Namboothiri, I. N. N.; Lewis, S. B.; Watson, W. H.; Bodige, S. G. Tetrahedron 1998, 54, 12691.

3. Marchand, A. P.; Zhao, D.; Ngooi, T.-K.; Vidyasagar, V.; Watson, W. H.; Kashyap, R. Tetrahedron 1993, 49, 2613.

4. Minter, D. E.; Smith, W. B.; Marchand, A. P.; Etukala, J. R.; Sivappa, R. J. Phys. Org. Chem. In press 2003.

5. Alder, K.; Wirtz, H.; Koppelberg, H. Liebigs Ann. Chem. 1956, 601, 138.

6. Bouboulis, C. J., J. Org. Chem. 1967, 32, 3540.

7. SAINT Version 6.02, Bruker Analytical X-ray Systems, Inc. Copyright 1997-1999.

8. SHELXTL Version 5.1 Bruker Analytical X-ray Systems, Inc. Copyright 1998. 